\title{
Behaviour of Superelastic Nickel Titanium Shape Memory Alloy Material under Uniaxial Testing and its Potential in Civil Engineering
}

\author{
Azmi Mohammad Hassan ${ }^{1}$, Raizal Saifulnaz Muhammad Rashid ${ }^{1, *}$, Nazirah Ahmad ${ }^{2}$, \\ Shahria Alam ${ }^{3}$, Farzad Hejazi ${ }^{1}$, and Nor Azizi Safiee ${ }^{1}$ \\ ${ }^{1}$ Department of Civil Engineering, Universiti Putra Malaysia, Serdang, Selangor, Malaysia \\ ${ }^{2}$ Malaysia Rubber Board, RRIM Experimental Station, Sungai Buloh, Selangor, Malaysia \\ ${ }^{3}$ School of Engineering, University of British Columbia, Kelowna, BC, Canada
}

\begin{abstract}
Smart structures are defined as structures that able to adapt and maintain structural characteristics in dealing with changes of external disturbance, environment and unexpected severe loadings. This ability will lead to improve structural safety, serviceability and structural life extension. Shape memory alloys is one of the smart materials which has potential to be integrated in structural system to provide functions such as sensing, actuation, self-adapting and healing of the structures. The unique characteristic of shape memory alloys material is the ability to 'remember' its original shape after deformation. Nickel Titanium superelastic shape memory alloy wire is popular and widely used in many engineering fields and owned fully recovery of maximum strain of 6\%$13.5 \%$ which is among the best shape recovery limit in alloy materials. The austenite finish temperature plays important role in stress-strain behaviour of superelastic shape memory alloys where higher stress required to complete martensite transformation with the increase of austenite finish temperature. The similar behaviour also is observed in the case of higher strain rate. The behaviour of superelastic shape memory alloys need to be studied before implementing in the structural system, so the targeted improvement for the structural system can be achieved.
\end{abstract}

\section{Introduction}

In civil engineering, researchers and engineers are actively studied on developing structural system which has ability to adapt with change in structural characteristics in response to variation of external loadings and environmental effects. It is necessary for the structural system to maintain its design performance against unexpected disturbance plus todays structures not only just meeting the need for functionality but there also the demand for slender and wide spanned structures [1]. In fulfilling todays requirement for adaptability, more secure and economical way to build structures, the concept of smart structures is an excellent model to be implemented in overcoming the limitations by conventional approach and one of the method is by integration of smart materials into the structural system. Shape

*Corresponding author: raizal@upm.edu.my 
memory alloy (SMA) is a smart material which widely used in many engineering fields such as aerospace, automotive and medical. In civil engineering, several researches have been done to investigate the potential of SMA material which resulting positive outcome in comparison with conventional approach. It unique functional alloy material which has ability to 'remember' its original form after deformation that attracts many researchers to utilize its capability in structural systems.

\section{Characteristics of superelastic shape memory alloys (SMAs)}

The behaviour of SMAs wires in regaining its original shape can be categorized in to two different characteristics known as superelasticity (pseudoelasticity) and shape memory effect. The characteristics of SMAs material are controlled by four critical temperatures known as Austenite Start $\left(\mathrm{A}_{s}\right)$, Austenite Finish $\left(\mathrm{A}_{f}\right)$, Martensite Start $\left(\mathrm{M}_{s}\right)$ and Martensite Finish $\left(\mathrm{M}_{f}\right)$ temperatures. Superelasticity is a phenomenon where shape recovery without residual deformation under large strain (6\%-13.5\%) and the shape is recovered upon unloading. The typical hysteresis behaviour of superelastic SMA as shown in Figure 1.

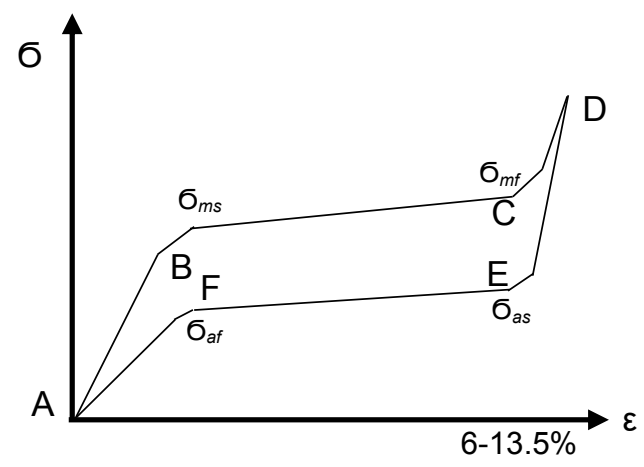

Fig. 1. Typical stress-strain hysteresis of superelastic SMA

The superelasticity behaviour of SMA can be observed in condition where the material temperature is higher than austenite $\operatorname{start}\left(A_{s}\right)$ temperature, however for fully recovery without residual deformation, the material temperature should to be higher than austenite finish $\left(A_{f}\right)$ temperature but below the martensite desist $\left(M_{d}\right)$ temperature [2]. In free load condition, the SMA material is in austenite phase but after the application of load, at martensite start temperature $\left(M_{s}\right)$ it begins the martensite transformation for conversion to austenite phase and at austenite finish temperature $\left(A_{f}\right)$, the material is in full austenite phase. The stage of A-B is where the elastic deformation of austenite phase and B-C is the phase for martensite transformation represents stress induced deformation from austenite to martensite. The increase of stress in C-D region only cause the elastic deformation of detwinned martensite and upon unloading, the D-E stage corresponds the elastic deformation of martensite phase. Subsequent unloading of E-F represents the austenite transformation which reverting the material to austenite phase $[3,4]$. The SMA strain recovery will return its original form at $\mathrm{A}$, which normally produced very small residual deformation, (e.g; $0.1 \%$ for NiTi).

\section{Ni-Ti SMA Characteristics}


There are few types of SMA material that commercially available and intensively studied in research works. Few of them that been extensively studied are Nickel (Ni), Copper $\mathrm{Cu}$ ) and Iron $(\mathrm{Fe})$ based SMA. The additional components are added to the system as secondary, tertiary, etc are added to the system such as Titanium (Ti) for Nickel based SMA to form SMA material known as Ni-Ti and aluminium (Al) and zinc ( $\mathrm{Zn})$ are added to $\mathrm{Cu}$ based SMA to form $\mathrm{Cu}-\mathrm{Al}-\mathrm{Zn}$. Among all three types of SMA materials, Ni-Ti is considered as the most popular and commercially available to be purchased. $\mathrm{Ni}-\mathrm{Ti}$ was discovered in 1962 by W.J Buehler and his research teams who are working to find a ductile, creep and fatigue resistant intermetallic compound at Naval Ordnance Laboratory [5] . The alloy was named as Nitinol as referring to Nickel Titanium Naval Ordnance Laboratory [6]. The remarkable finding had led to numerous research continuous research on the potential of Ni-Ti SMA material. There are several factors affecting the performance of superelastic NiTi materials as described in next sub-sections;

\subsection{Alloy composition}

The composition of $\mathrm{Ni}$ and $\mathrm{Ti}$ in the $\mathrm{Ni}-\mathrm{Ti}$ system will affect the austenite finish temperatures $\left(A_{f}\right)$. An increase of Nickel composition will lowering the $A_{f}$ temperature [6]. The variation of $A_{f}$ temperatures will lead to changes in hysteresis after subjected to loading and unloading mechanism.

\subsection{Transition Temperature}

The variation of transition temperature (austenite finish), $A_{f}$ will affect the performance of Ni-Ti SMA material. The Ni-Ti SMA material with has closest different between austenite finish temperature and testing temperature will be able to withstand more cycles and on opposite side which has larger different in both of temperature, it will produce lower fatigue life and higher plateau stress [7]. Also, the increase of $A_{f}$ temperature will lead to decrease of material upper plateau stresses.

\section{Experimental Results and Discussion}

Several Ni-Ti wires have been purchased from Kellogg's Research Labs and subjected to uniaxial test using Instron tensile test machine. The wires selected comprised few different characteristics as shown in Table 1 .

Table 1. Material Details

\begin{tabular}{|c|c|c|c|c|c|c|}
\hline No & SMA & Label & $\begin{array}{c}\text { Austenite } \\
\text { Finish Temp, } \\
\text { Af }\end{array}$ & $\begin{array}{c}\text { Diameter, } \\
\mathbf{m m}\end{array}$ & $\begin{array}{c}\text { Test Temp, } \\
{ }^{\circ} \mathbf{C}\end{array}$ & $\begin{array}{c}\text { Behaviour, } \\
\mathbf{T}\end{array}$ \\
\hline 1 & Ni-Ti & S1 & -15 & 0.5 & 28 & SE \\
\hline 2 & Ni-Ti & S2 & -15 & 1 & 28 & SE \\
\hline 3 & Ni-Ti & S3 & 20 & 1 & 28 & SE \\
\hline 4 & Ni-Ti & S4 & 45 & 1 & 28 & SME \\
\hline
\end{tabular}

Referring to Table 1, tensile test conducted on Ni-Ti wire with for categories labelled as $S 1, S 2, S 3$ and $S 4$. S1 represents SMA wire with $A_{f}$ temperature of $-15^{\circ} \mathrm{C}$ with diameter $0.5 \mathrm{~mm}$ and $\mathrm{S} 2$ wire have similar $A_{f}$ to $\mathrm{S} 1$ but with diameter of $1.0 \mathrm{~mm}$. S3 and S4 are the Ni-Ti SMA wires with $A_{f}$ temperature of $20^{\circ} \mathrm{C}$ and $45^{\circ} \mathrm{C}$ and out of all wires, S4 wire is the 
only wire with $A_{f}$ temperature higher than testing temperature, $T$ which will exhibit residual after deformation and in this case, it required external heating to recover its shape which is not conducted in this experimental work and it is considered as shape memory effect (SME) behaviour. S1 to S3 wires are considered as superelastic (SE) behaviour as the $A_{f}$ temperature is lower than testing temperature $\left(A_{f}<\mathrm{T}\right)$. The result for the tensile test is shown in Table 2 and Table 3;

Table 2. Uniaxial test at $6 \%$ strain

\begin{tabular}{|c|c|c|c|c|c|}
\hline No & Label & $\begin{array}{c}\text { Initial Length, } \\
\text { L1,mm }\end{array}$ & $\begin{array}{l}\text { Final length } \\
\text { after recovery } \\
\mathbf{m m}\end{array}$ & $\begin{array}{c}\text { Deformation, } \\
\mathbf{m m}\end{array}$ & Recovery, \% \\
\hline 1 & S1 & 150 & 150 & 9.0 & 100 \\
\hline 2 & S2 & 150 & 150 & 9.0 & 100 \\
\hline 3 & S3 & 150 & 150.5 & 9.0 & $94 \%$ \\
\hline 4 & S4 & 150 & 160 & 9.0 & 0 \\
\hline
\end{tabular}

Table 3. Uniaxial test at $8 \%$ strain

\begin{tabular}{|c|c|c|c|c|c|}
\hline No & Label & $\begin{array}{c}\text { Initial Length, } \\
\text { L1,mm }\end{array}$ & $\begin{array}{l}\text { Final length } \\
\text { after recovery } \\
\mathbf{m m}\end{array}$ & $\begin{array}{c}\text { Deformation, } \\
\mathbf{m m}\end{array}$ & Recovery, \% \\
\hline 1 & S1 & 150 & 150 & 12.0 & 100 \\
\hline 2 & S2 & 150 & 150 & 12.0 & 100 \\
\hline 3 & S3 & 150 & 151 & 12.0 & 94 \\
\hline 4 & S4 & 150 & 162 & 12.0 & 0 \\
\hline
\end{tabular}

Table 2 and Table 3 exhibit the deformation results after the SMA wires are subjected to $6 \%$ and $8 \%$ strain. For tensile test up to $6 \%$ strain, S1,S2,S3 wires with superelastic has displayed excellent recovery to origin form and S4 wire with SME characteristic does not recovered to origin length. When subjected up to $8 \%$ strain, $\mathrm{S} 1$ wire with $0.5 \mathrm{~mm}$ diameter is completely recover and S2 superelastic wire resulted full recovery while S3 recovered at $94 \%$ which only $1 \mathrm{~mm}$ residual deformation after subjected to $12.0 \mathrm{~mm}$ strain. S4 wire with SME effect has displayed similar behaviour as in $6 \%$ recovery where it does not recover at all, which in this case, it required heating above Af temperature for recovery to its origin form.

In this experimental work, the tensile test only covers for loading phase since there was problem with machine in plotting unloading phase. In loading phase, only the stress at martensite start and finish ( $\sigma \mathrm{ms}, \sigma \mathrm{mf})$ can be estimated. The stress-strain curves for superelastic wire range (S1-S3) are shown in Figure 2. 


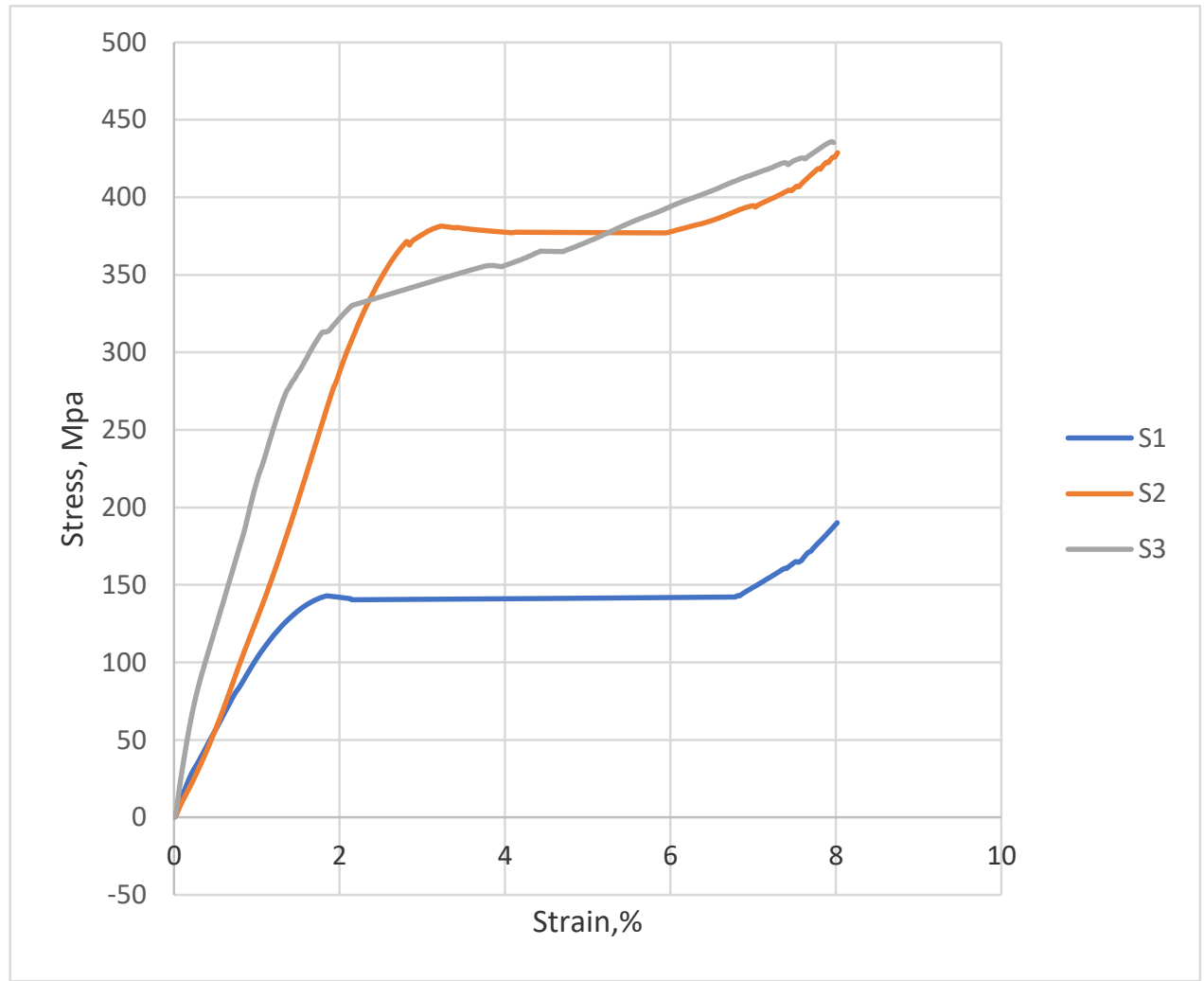

Fig. 2. Stress-Strain curve for superelastic SMA

From Figure 2 stress strain curve, the stress data for martensite start and finish can be estimated and the details are tabulated in Table 4.

Table 4. $\sigma_{\mathrm{ms}}$ and $\sigma_{\mathrm{mf}}$ for superelastic SMA up to $8 \%$ maximum strain

\begin{tabular}{|c|c|c|c|}
\hline No & SMA & $\boldsymbol{\sigma}_{\boldsymbol{m} \boldsymbol{s}}, \mathbf{M p a}$ & $\boldsymbol{\sigma}_{\boldsymbol{m} \boldsymbol{f},}, \mathbf{M p a}$ \\
\hline 1 & S1 & 142 & 188 \\
\hline 2 & S2 & 360 & 431 \\
\hline 3 & S3 & 330 & 435 \\
\hline
\end{tabular}

Figure 2 and Table 4 displayed the stress- strain curves and stress data at martensite transformation (loading phase). For S1 wire with $0.5 \mathrm{~mm}$ diameter, it required less than $50 \%-60 \%$ stress to complete martensite transformation in compared with S1 wire with $1 \mathrm{~mm}$ diameter. Higher Af temperature will require higher stress at martensite start, 6ms which meaning it required higher force to activate martensite transformation. However, at martensite finish, superelastic wires with higher Af temperature required higher force to complete martensite transformation and detwinning.

In many applications especially in civil engineering, as example in vibration analysis which consists variation of frequency and it is necessary to study behaviour of superelastic SMA under different strain rate. In this experimental work, S2 and S3 wires are subjected to strain rate of $1 \mathrm{~mm}$ per second and $2 \mathrm{~mm}$ per second and comparison of both results of are shown in Figure 3. 


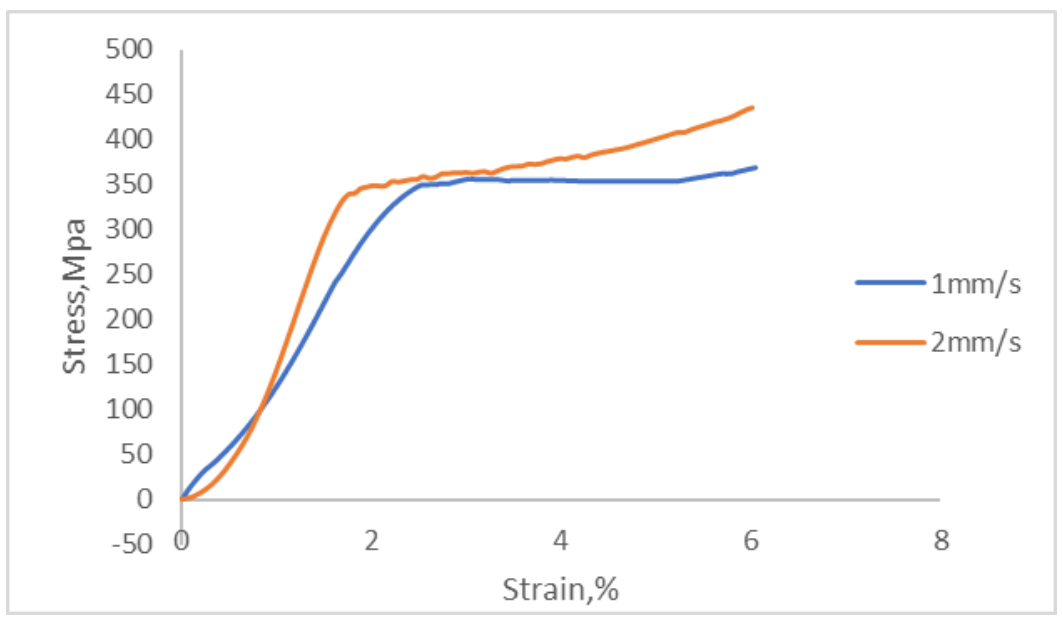

Fig. 3. $\mathrm{S} 2$ wire at $1 \mathrm{~mm} / \mathrm{s}$ and $2 \mathrm{~mm} / \mathrm{s}$

Table 5 exhibits the estimated stress data at martensite start and finish after being applied with different strain rates.

Table 5. $\sigma_{\mathrm{ms}}$ and $\sigma_{\mathrm{mf}}$ at different strain rate

\begin{tabular}{|c|c|c|c|c|c|}
\hline \multirow{2}{*}{ No } & \multirow{2}{*}{ Stress } & \multicolumn{2}{|c|}{ S2 } & \multicolumn{2}{c|}{ S3 } \\
\cline { 3 - 6 } & & $\mathbf{1 m m} / \mathbf{s}$ & $\mathbf{2 m m} / \mathbf{s}$ & $\mathbf{1 ~ m m} / \mathbf{s}$ & $\mathbf{2 m m} / \mathbf{s}$ \\
\hline 1 & $\boldsymbol{\sigma}_{\boldsymbol{m} \boldsymbol{s}}, \mathrm{Mpa}$ & 341 & 356 & 292 & 217 \\
\hline 2 & $\boldsymbol{\sigma}_{\boldsymbol{m} \boldsymbol{f}, \mathrm{Mpa}}$ & 368 & 436 & 427 & 508 \\
\hline
\end{tabular}

Figure 3 and Table 5 displayed the result at different strain rate $(1 \mathrm{~mm} / \mathrm{s}$ and $2 \mathrm{~mm} / \mathrm{s})$ where higher strain rate will result higher force required to complete martensite transformation in compared with the lower strain rate. This behaviour indicated with the addition of SMA in the structural system, it will increase the stiffness which can control the system when subjected to high vibration frequency.

\section{SMAs material in civil engineering}

SMA materials have being utilized intensively in aerospace and medical engineering and the unique characteristics of the material have gained attention for researchers in civil engineering field. [8] conducted studied on performance of rectangular laminated natural rubber bearing (SR1) with SMA and compared with high damping rubber bearing (HDRB) without SMA on bridge structure. For pier displacement, he found that SR1 experience $21 \%$ less than HDRB on moderate earthquake and similar behaviour also can be observed for strong earthquake. SR1 also produce lower residual deformation in compared with HDRB for both moderate and strong earthquake. [9] conducted study on lead rubber bearing (LRB) fitted with SMA and compared with conventional LRB which he found that at shear strain level lower than $50 \%$, both types of LRB exhibits similar behaviour, however for shear strain beyond than 50\% SMA based LRB resulted higher energy dissipation and lateral stiffness. For re-centering capability, SMA LRB exhibits better recentering capability by reducing its residual deformation up to $33 \%$. [10] also conducted research on bridge column by replacing the steel reinforcement with superelastic shape memory alloys. They found that normal RC column has result 33\% residual drift in 
compared with SMA column. [11] proposed performance-based seismic design (PBSD) using SMA alloy as kernel component for self-centering steel braced (SMAB). A six-story building was designed and equipped with $\mathrm{SMAB}$ and examined and various seismic intensity level. From the result, they found that SMAB exhibits favourable self-centering and energy dissipation capabilities. In addition, it also resulted limited structural damage and permanent deformation after strong earthquake intensity. [12] designed and simulated the SMA based Tuned Mass Dampers (SMA-TMD) as a passive control device which composed of mass, damping device and restoring mechanism. In performance comparison between conventional linear TMD, SMA-TMD exhibited enhanced control efficiency and reduce the displacement of the device itself. Plus, under seismic assessment on structures, SMA-TMD eliminated the residual displacement of conventional TMD. From all previous researches conducted by other researchers, the inclusion of SMA material in the seismic devices and as an integrated element in structural member design has proved to improve conventional design in important aspects such as elimination of residual deformation, improvement in energy dissipation and provided better protection to structural members especially in a strong earthquake condition. Despite superior performance for SMA based system, the limitation of the material still a biggest challenge in designing the system as it is only works if the system design workability within the maximum recovery limit of SMA itself; eg Ni-Ti (6\%-8\%). Plus, the SMA material is very sensitive to temperature, which the behaviour of the SMA material under temperature variation need to be well understood prior implementation in civil engineering components. Apart of that, the fatigue of SMA material also still a major concern and needed to be taken into consideration even though its fatigue behaviour still not yet well understood [13].

\section{Conclusion}

From the experimental work, it can be observed that superelastic Ni-Ti SMA can be beneficial to be utilized as part of components in structural system especially in improving conventional approach performance in terms of properties such as re-centering capability, energy dissipation and reducing residual deformation. The excellent recovery within 6\%$8 \%$ maximum strain and higher loading requirement at higher strain rate have shown that superelastic Ni-Ti has great potential to be used in civil engineering and it is essential to understand behaviour of SMA material, so it can be fitted properly into targeted structural system.

This work has been supported and funded using Geran Putra - Inisiatif Putra Siswazah (IPS) which granted by Universiti Putra Malaysia (UPM).

\section{References}

1. Stoeckel, D., SMA for Power System EPRI Proceeding, (Issue),(1995)

2. Lagoudas, D.C., Springer,(2008)

3. Nemat-Nasser, S. and W.-G. Guo, Mechanics of Materials, 38(5),(2006)

4. Brook, G.B., Materials \& Design, 4(4),(1983)

5. Mihálcz, I., Periodica Polytechnica, Mechanical Engineering, 45(1),(2001) 
6. Patel, M., et al., ASM Material \& Processes for Medical Devices Conference \& Exposition (MPMD), 2006)

7. Rahman Bhuiyan, A. and M.S. Alam, Engineering Structures, 49(2013)

8. Dezfuli, F.H. and M.S. Alam, Structural Control and Health Monitoring, 24(2),(2017)

9. M. Saiid Saiidi, M.O.B. and S.-Z. Mahmoud, ACI Structural Journal, 106(1),(2009)

10. Hou, H., et al., Structural Control and Health Monitoring, 25(3),(2018)

11. Qiu,C.X and Zhu,S, Engineering Structures, 130 (2017)

12. Bhowmick, S. and S.K. Mishra, Adv. In Strc Engr,Springer,(2015)

13. Bhaumik, S.K., Transactions of the Indian Institute of Metals, 61(5),(2008) 